\title{
A New Photolabile Linker for the Photoactivation of Carboxyl Groups
}

\author{
K. C. Nicolaou,* Brian S. Safina, Nicolas Winssinger
}

Department of Chemistry and The Skaggs Institute for Chemical Biology, The Scripps Research Institute, 10550 North Torrey Pines Road, California 92037, and Department of Chemistry and Biochemistry, University of California, San Diego, 9500 Gilman Drive, La Jolla, California 92093, USA

Fax +1 (858) 7842469; E-mail: kcn@scripps.edu

Received 17 September 2000

\begin{abstract}
A new photolabile linker enabling nucleophilic cleavage of a carboxyl functionality upon irradiation with UV light (>290 $\mathrm{nm})$ was developed. When the photocleavage is carried out in the presence of primary or secondary amines, amides are obtained in high yields and purities, while the intramolecular version of this reaction leads to heterocycles via a cyclorelease mechanism.
\end{abstract}

Key words: solid phase synthesis, photolabile linker, amides, cyclizations

The scope of combinatorial chemistry is constantly expanding by the development of new linkers ${ }^{1}$ capable of allowing for the facile adoption of new synthetic strategies on solid phase. A rich repertoire of such linkers is necessary in order to provide the practitioner with the opportunity of orthogonality often needed to achieve the desired selectivity for solid phase library construction. Photolabile linkers are particularly attractive by virtue of the green chemistry conditions associated with their cleavage, rendering them compatible with most functional groups found in biologically relevant compounds. ${ }^{2}$

In an effort to develop a photolabile linker for deployment in cyclorelease and related strategies, we considered the unique photochemical properties of the 5-bromo-7-nitroindoline (Bni) moiety $\mathbf{1}$, first introduced by Amit et al. in $1976^{3}$ (Scheme 1) and subsequently employed in peptide synthesis and photorelease of carboxylic acids. ${ }^{4}$

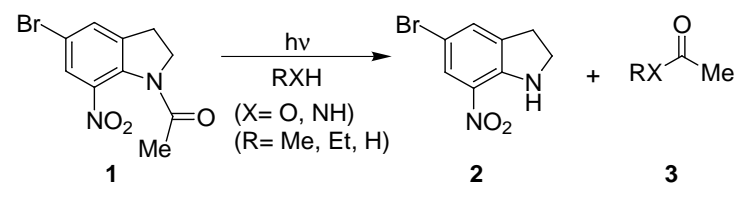

Scheme 1 Photocleavage of the 5-bromo-7-nitroindoline (Bni) group

In addition to serving as a protecting group, ${ }^{5}$ the Bni group has the ability to activate the amide carbonyl group towards nucleophilic attack by hydroxy or amino compounds upon irradiation with UV light (see Scheme 1).

The proposed mechanistic rationale, depicted in Scheme 2 , begins with photoexcitation of the starting bromoindoline amide 4 to a highly reactive species 5 which undergoes rapid acyl transfer from the indoline nitrogen to the

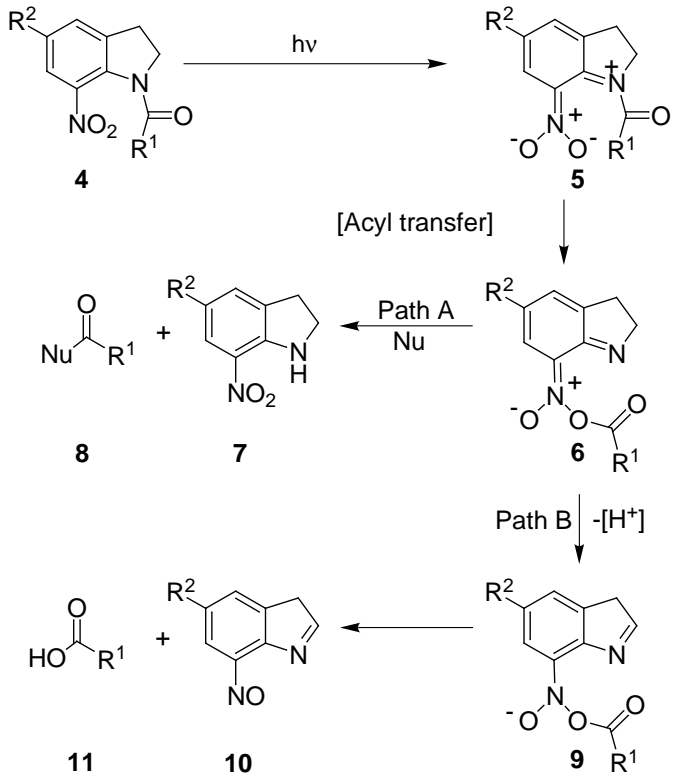

Scheme 2 Photolytic fragmentation pathways (A and B) of 1-acyl-7-indolines

adjacent nitro group oxygen $\mathbf{5} \rightarrow \mathbf{6} .^{6,7}$ The resulting species 6 has two options available to it, both of which result in the species regaining aromaticity (Scheme 2). Thus, in the presence of a nucleophile $\left(\mathrm{ROH}\right.$ or $\left.\mathrm{RNH}_{2}\right)$, the now activated carboxyl group may react to afford an ester or an amide $\mathbf{8}$ and indoline $\mathbf{7}$ (Path A) or it can lose a proton and provide $\mathbf{9}$ which collapses to the carboxylic acid $\mathbf{1 1}$ and nitroso indoline $\mathbf{1 0}$ (Path B). It was shown that in aqueous media pathway $\mathrm{B}$ predominates over nucleophilic attack, whereas in organic solvents containing traces of water (ca. 1\%) pathway A dominates thereby releasing the carboxylic acid. ${ }^{7}$

Our interest in the Bni group stemmed from its ability to photochemically activate the otherwise robust amide functionality towards nucleophilic attack, and hence lead to an efficient photolabile linker. It was envisioned that such a linker would be capable of both intermolecular cleavage as well as cyclorelease via an intramolecular ring closure.

In the process of creating a solid phase version of the Bni group 1, preliminary experiments suggested that a substituent capable of deactivating the aromatic ring at 

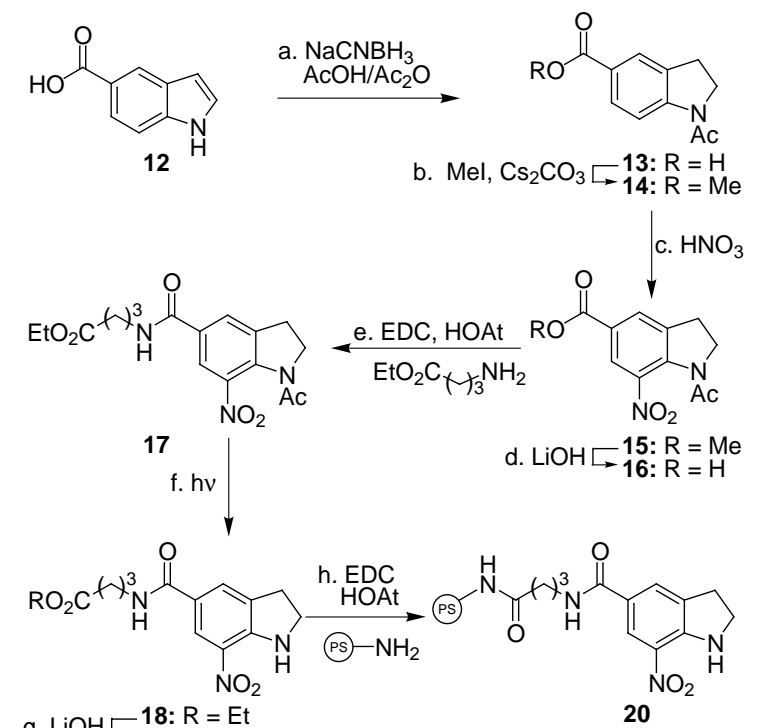

g. $\mathrm{LiOH} \square$ 18: $\mathrm{R}=\mathrm{Et}$

Conditions: (a) 2.0 equiv of $\mathrm{NaCNBH}_{3}, \mathrm{AcOH}, 20 \mathrm{~min}$; then $\mathrm{HCl}$, $\mathrm{Ac}_{2} \mathrm{O}, 23^{\circ} \mathrm{C}, 6 \mathrm{~h}$; (b) 10 equiv of MeI, 1 equiv of $\mathrm{Cs}_{2} \mathrm{CO}_{3}$, DMF, 50 ${ }^{\circ} \mathrm{C}, 3 \mathrm{~h}, 53 \%, 2$ steps; (c) $\mathrm{HNO}_{3} / \mathrm{C}_{2} \mathrm{H}_{4} \mathrm{Cl}_{4}(1: 2), 50{ }^{\circ} \mathrm{C}, 1.5 \mathrm{~h}, 80 \%$; (d) 2.0 equiv of $\mathrm{LiOH}, \mathrm{THF} / \mathrm{H}_{2} \mathrm{O}(1: 1), 50{ }^{\circ} \mathrm{C}, 4 \mathrm{~h}$; (e) 1.1 equiv of EDC, 1.1 equiv of HOAt, 1.1 equiv of $\mathrm{EtO}_{2} \mathrm{C}\left(\mathrm{CH}_{2}\right)_{3} \mathrm{NH}_{3} \mathrm{Cl}$, DMF, $25^{\circ} \mathrm{C}$, $12 \mathrm{~h}, 83 \%, 2$ steps; (f) hv (pyrex filter), $\mathrm{CH}_{2} \mathrm{Cl}_{2} /$ dioxane $/ \mathrm{H}_{2} \mathrm{O}$ (2:3:0.05), $6 \mathrm{~h}, 85 \%$; (g) 1.5 equiv of $\mathrm{LiOH}, \mathrm{THF} / \mathrm{H}_{2} \mathrm{O}(1: 1), 25^{\circ} \mathrm{C}$, $4 \mathrm{~h}$; (h) 3.0 equiv of EDC, 3.0 equiv of HOAt, 1.0 equiv of aminomethylated polystyrene $(0.60 \mathrm{mmol} / \mathrm{g}), \mathrm{DMF}, 25^{\circ} \mathrm{C}, 24 \mathrm{~h}, 0.43$ $\mathrm{mmol} / \mathrm{g}$. Abbreviations: $\mathrm{DMF}=N, N$-dimethylformamide. THF $=$ tetrahydrofuran. $\quad \mathrm{EDC}=1$-(3-dimethylamino-propyl)-3ethylcarbodiimide $\cdot \mathrm{HCl}$. HOAt $=1$-hydroxy-7-azabenzotriazole.

Scheme 3 Synthesis of the new photolabile linker 20

the 5-position favored the desired cleavage pathway A (see Scheme 2). Thus, synthesis of the suitable linker (Scheme 3) began with $\mathrm{NaCNBH}_{3}$ reduction of the commercially available 5-carboxylic acid indole 12, followed by methylation of the resulting carboxylic acid 13 with $\mathrm{Cs}_{2} \mathrm{CO}_{3}-\mathrm{MeI}$ to furnish ester 14. Substrate-directed nitration at the 7-position with concentrated nitric acid gave the nitro indoline 15. Insertion of a four-carbon spacer via ester hydrolysis and standard EDC coupling led to ester 17 via 16. Photo-removal of the acyl group from 17, followed by saponification and subsequent attachment to aminomethylated polystyrene resin (1\% cross-linked, 100-200 mesh) through EDC coupling completed the synthesis of indoline $\mathbf{2 0}$ (via $\mathbf{1 8}$ and 19), with an overall loading of $0.43 \mathrm{mmol} / \mathrm{g}$ as estimated by mass gain.

To illustrate the utility of this new resin (20), a number of groups capable of undergoing cyclorelease or intermolecular coupling release were loaded on as shown in Scheme 4. Thus, treatment of $\mathbf{2 0}$ with phosgene led to $\mathbf{2 1}$ which furnished 22 upon reaction with ethylenediamine in the presence of 4-DMAP. On the other hand, derivatization of 20 with chloroacetyl chloride allowed the loading of a number of carboxylic acids via intermediate 23. Thus, the reaction of 23 with $\mathrm{PhCO}_{2} \mathrm{H}$, BocNHCHBnCO${ }_{2} \mathrm{H}$,

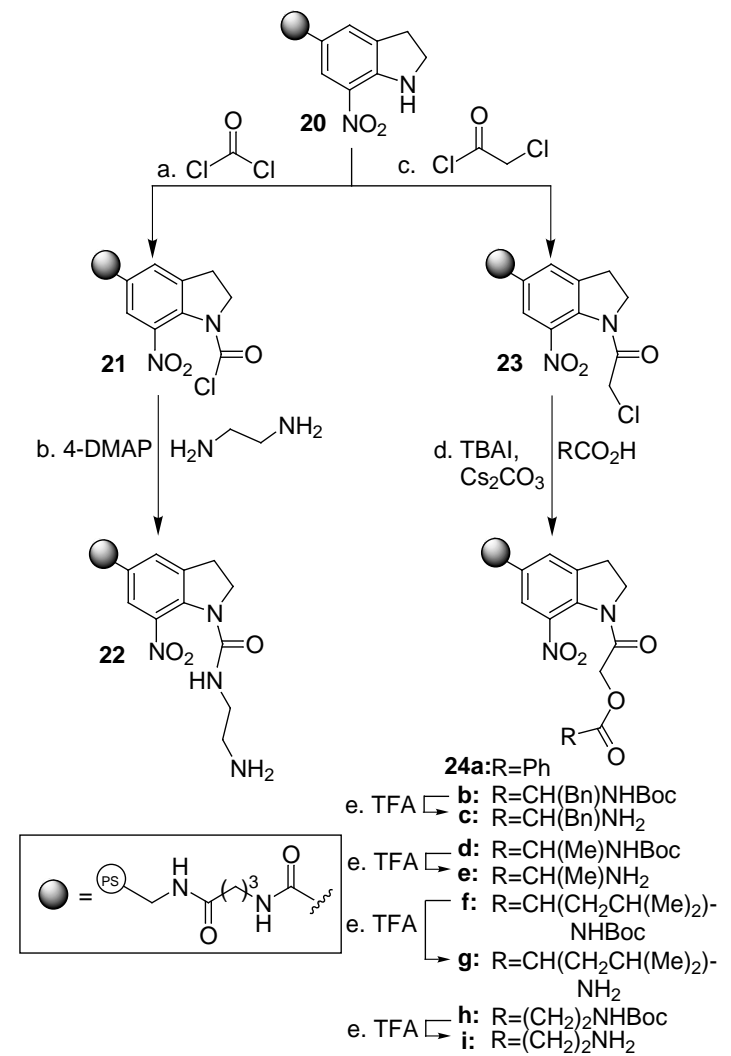

Conditions: (a) 50 equiv of $\mathrm{COCl}_{2}, 25$ equiv of 4-DMAP, DMF, 25 ${ }^{\circ} \mathrm{C}, 1 \mathrm{~h}$; (b) 50 equiv of $\mathrm{NH}_{2} \mathrm{CH}_{2} \mathrm{CH}_{2} \mathrm{NH}_{2}, 25$ equiv of 4-DMAP, $\mathrm{CH}_{2} \mathrm{Cl}_{2}, 2{ }^{\circ} \mathrm{C}, 1 \mathrm{~h}$; (c) 50 equiv of $\mathrm{ClCOCH}_{2} \mathrm{Cl}, 25$ equiv of 4DMAP, DMF, $25^{\circ} \mathrm{C}, 6 \mathrm{~h}$; (d) 25 equiv of $\mathrm{RCO}_{2} \mathrm{H}, 2.5$ equiv of TBAI, 25 equiv of $\mathrm{Cs}_{2} \mathrm{CO}_{3}, \mathrm{DMF}, 60^{\circ} \mathrm{C}, 12 \mathrm{~h}$; (e) $25 \%$ TFA in $\mathrm{CH}_{2} \mathrm{Cl}_{2}, 25$ ${ }^{\circ} \mathrm{C}, 30 \mathrm{~min}$. Abbreviations: $\mathrm{PS}=$ polystyrene. 4 -DMAP $=4$-(dimethylamino)pyridine. $\mathrm{DMF}=N, N$-dimethyl formamide. $\mathrm{TBAI}=$ tetra$n$-butylammonium iodide. TFA $=$ trifluoroacetic acid.

Scheme 4 Solid phase synthesis of resin conjugates

$\operatorname{BocNHCH}(\mathrm{Me}) \mathrm{CO}_{2} \mathrm{H}$, BocNHCH$\left(\mathrm{CH}_{2} \mathrm{CH}(\mathrm{Me})_{2}\right) \mathrm{CO}_{2} \mathrm{H}$, BocNHCH $\mathrm{CH}_{2} \mathrm{CO}_{2} \mathrm{H}$ in the presence of $\mathrm{Cs}_{2} \mathrm{CO}_{3} / n-\mathrm{Bu}_{4} \mathrm{NI}$ led to conjugates $\mathbf{2 4 a}, \mathbf{2 4 b}, \mathbf{2 4 d}, \mathbf{2 4 f}$ and $\mathbf{2 4 h}$, respectively. Exposure of these compounds to TFA produced the free amines 24c, 24e, 24g and 24i, respectively.

Preliminary solution phase intermolecular cleavage experiments of the nonpolymer-bound counterpart of $\mathbf{2 4 a}$ with various primary and secondary amines resulted in efficient conversion $(>95 \%)$ to the desired amide product. However, when methanol was used as a nucleophile, a mixture of the carboxylic acid (see Scheme 2) and the ester were obtained along with decomposition products. In light of these findings, only amines were chosen for initial solid phase photorelease studies.

Table 1 illustrates the generality and scope of the photocleavable linker with a number of primary and secondary amines $(\mathbf{2 5 a}-\mathbf{g})$. Depending on the nucleophilicity and steric environment of the amino group, yields ranging from $67-95 \%$ and purities over $90 \%$ were observed. 
Table 1 Intermolecular photocleavage with amines ${ }^{\mathrm{a}}$

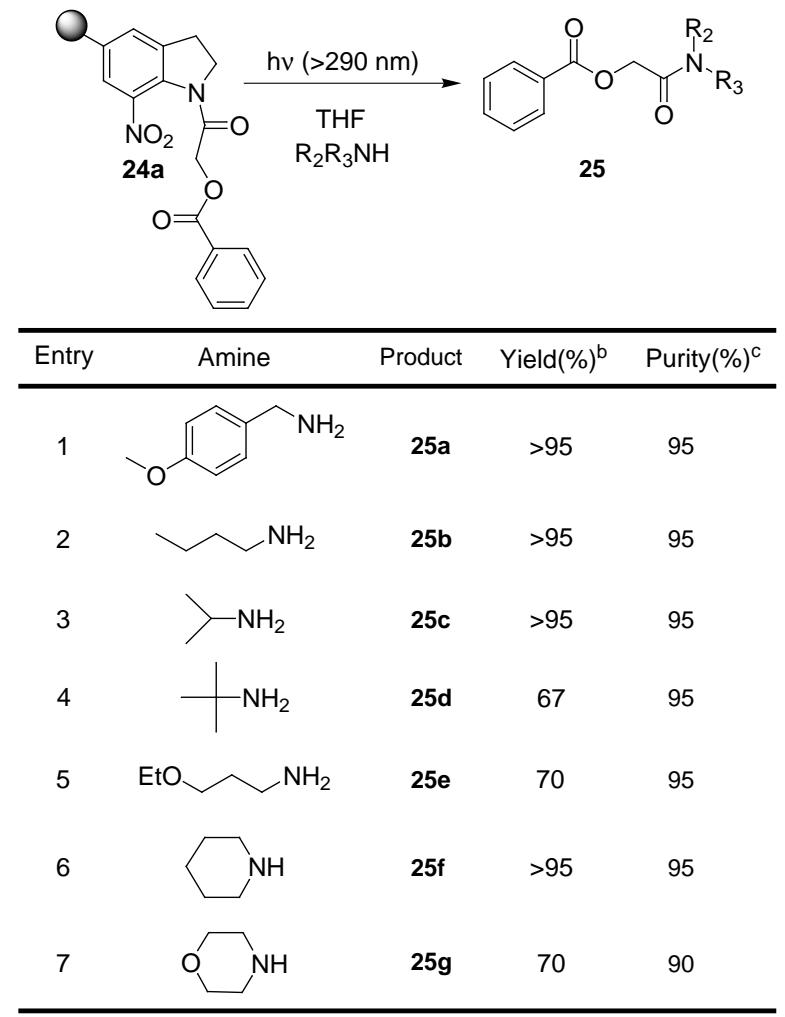

${ }^{\mathrm{a} C o n d i t i o n s: ~(a) ~ G e n e r a l ~ P r o c e d u r e: ~ T o ~ a ~ s u s p e n s i o n ~ o f ~} \mathbf{2 4 a}$ (30 mg, $0.013 \mathrm{mmol})$ in THF ( $3 \mathrm{~mL}$ ) was added an amine (10 equiv or further excess if volatile) and irradiated with UV light (450W, Hg, 4.3" arc lamp, Ace Glass Inc.; 7830-60 power supply, Ace Glass Inc.), wave length $>290 \mathrm{~nm}$ (lamp equipped with pyrex filter), while stirring for $6-12 \mathrm{~h}$ at $25^{\circ} \mathrm{C}$

${ }^{b}$ Yields are for chromatographically and spectroscopically pure compounds.

cPurity was estimated by integration of ${ }^{1} \mathrm{H}$ NMR signals.

Intramolecular photo-induced cycloreleases were also demonstrated with a number of resins as shown in Table 2. Especially notable are the cycloreleases of $24 \mathbf{c}$ and $24 \mathbf{e}$ (entries 2 and 3), leading to the corresponding 6-membered heterocycles in high yields and purities. In an attempt to form macrocycles by this reaction, however, we observed a significant drop in efficiency as demonstrated with entry 5 , Table 2 . Formation of the 7-membered heterocycle 26e proceeded only in ca. 50\% yield and ca. $50 \%$ purity, the product being contaminated with the acyclic carboxylic acid (see Scheme 2).

In conclusion, we have constructed a novel polystyrenebased photolabile linker based on the Bni moiety (1) and demonstrated its utility in loading a number of building blocks for further elaboration. Photo-induced releases of a variety of compounds were also demonstrated utilizing a variety of external or internal nucleophiles (e.g. amines) to produce amides or lactams, respectively. Further explorations along these lines may lead to useful applications to organic synthesis and combinatorial chemistry.
Table 2 Intramolecular photocyclizations ${ }^{\mathrm{a}}$

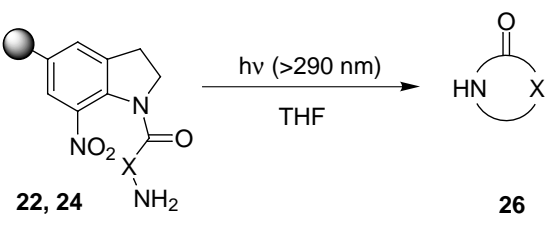

\begin{tabular}{lllll}
\hline Entry & Resin & Yield $(\%)^{\mathrm{b}}$ & Purity $(\%)^{\mathrm{c}}$ \\
\hline 2 & 22 & & \\
\hline
\end{tabular}

${ }^{\mathrm{a}}$ Conditions: General Procedure: A suspension of 24c (30 mg, 0.013 $\mathrm{mmol})$ in THF ( $3 \mathrm{~mL})$ was irradiated with UV light $\left(450 \mathrm{~W}, \mathrm{Hg}, 4.3^{\prime \prime}\right.$ arc lamp, Ace Glass Inc.; 7830-60 power supply, Ace Glass Inc.), wave length $>290 \mathrm{~nm}$ (lamp equipped with pyrex filter), while stirring for 6-12 $\mathrm{h}$ at $25^{\circ} \mathrm{C}$.

${ }^{b}$ Yields of entries 1-4 are for chromatographically and spectroscopically pure compounds.

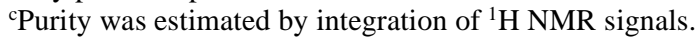

${ }^{\mathrm{d}}$ Yield estimated by integration of ${ }^{1} \mathrm{H}$ NMR signals.

\section{Acknowledgement}

We thank Jeffrey A. Pfefferkorn for helpful discussions. This work was financially supported by The Skaggs Institute for Chemical Biology, the National Institutes of Health (USA) and the George Hewitt Foundation (fellowship to N. N.).

\section{References and Notes}

(1) Guillier, F.; Orain, D.; Bradley, M. Chem. Rev. 2000, 100, 2091.

(2) For examples see: (a) Hong Boon, L.; Balasubramanian, S. J. Org. Chem. 1999, 64, 5728. (b) Hong Boon, L.; Balasubramanian, S. J. Org. Chem. 1999, 64, 3454.

(c) Akerblom, E. B. Mol. Diversity 1999, 4, 53. (d) Peukert, S.; Giese, B. J. Org. Chem. 1998, 63, 9045. (e) Sternson, S. M.; Schreiber, S. L. Tetrahedron Lett. 1998, 39, 7451.

(f) Rodebaugh, R.; Fraiser-Reid, B.; Geysen, H. M

Tetrahedron Lett. 1997, 38, 7653. (g) Routledge, A.; Abell, C.; Balasubramanian, S. Tetrahedron Lett. 1997, 38, 1227. 
(h) Roussel, P.; Bradley, M.; Matthews, I.; Kane, P. Tetrahedron Lett. 1997, 38, 4861. (i) Holmes, C. P. J. Org. Chem. 1997, 62, 2370. (j) Holmes, C. P.; Jones, D. G. J. Org. Chem. 1995, 60, 2318.

(3) Amit, B.; Ben-Efraim, D. A.; Patchornik, A. J. Am. Chem. Soc. 1976, 98, 843 .

(4) Pass, S.; Amit, B.; Patchornik, A. J. Am. Chem. Soc. 1981, $103,7674$.

(5) Greene, T. W.; Wuts, P. G. M. Protective Groups in Organic Synthesis; $3^{\text {rd }}$ Ed., John Wiley \& Sons, Inc.: New York, 1999; Ch. 5, p 448.
(6) Amit, B.; Ben-Efraim, D. A.; Patchornik, A. J. Chem. Soc., Perkin Trans. 1 1976, 57.

(7) Papageorgiou, G.; Ogden, D. C.; Barth, A.; Corrie, J. E. T. J. Am. Chem. Soc. 1999, 121, 6503.

Article Identifier:

1437-2096,E;2001,0,SI,0900,0903,ftx,en;Y17000ST.pdf 